\title{
The Position Effect of Fatty Acid Modification on the Cytotoxicity and Anti- metastasis Potential of the Cytotoxic Peptide Lycosin-I
}

Peng Zhang ${ }^{1,2 \uparrow}$, Cui Jiann ${ }^{2 \dagger}$, Shandong Jian ${ }^{1}$, Qianqian Zhang ${ }^{1}$, Xiaoliang $\mathrm{Sun}^{2}$, Liqin $\mathrm{Nie}^{2}$, Bobo $\mathrm{Liu}^{2}$, Fengjiao $\mathrm{Li}^{1}$, Jinting $\mathrm{Li}^{1}$, Meiyan $\mathrm{Liu}^{2}$, Songping Liang ${ }^{1}$, Youlin Zeng ${ }^{2 *}$ and Zhonghua $\operatorname{Liu}^{1,3^{*}}$

1. The National \&Local Joint Engineering Laboratory of Animal Peptide Drug Development, College of Life Sciences, Hunan Normal University, Changsha Hunan 410081, China. Email:liuzh@hunnu.edu.cn

2. The National and Local Joint Engineering Laboratory for New Petrochemical Materials and Fine Utilization of Resources, Hunan Normal University, Changsha Hunan 410081, China. E-mail: youlinzengcn@gmail.com

3. State Key Laboratory of Developmental Biology of Freshwater Fish, College of Life Sciences, Hunan Normal University, Changsha Hunan 410081, China

${ }^{*}$ Corresponding author

${ }^{\dagger}$ These authors contribute equally to this paper.

\section{Table of content}

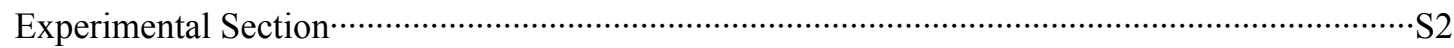

Characterization and purification of dodecanoic acid modified peptide $\cdots \cdots \cdots \cdots \cdots \cdots \cdots \cdots \cdots \cdots \cdots \cdots \cdots \cdots \cdots \cdots . . .52$

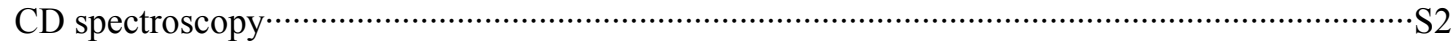

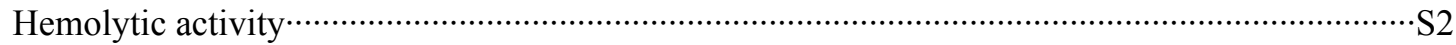

Figure S1. Analytical RP-HPLC and mass spectra of lipopeptides …………………………...S3-S5

Figure S2. The cytotoxicity of Lycosin-I and lipopeptides to HEK293T cells ……………….......S5

Figure S3. Live cell statistics of trypan blue staining experiments ………………………….....S5

Figure S4. Hemolytic activity of Lycosin-I and lipopeptides against human erythrocytes ………S6

Figure S5. The secondary structure of Lycosin-I and eight lipopeptides …………………….....S6

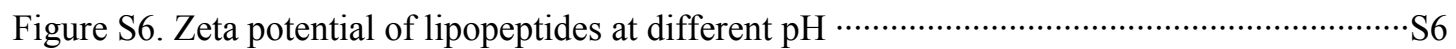

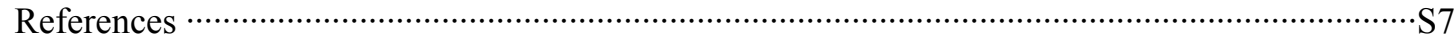




\section{Experimental Section}

\section{Characterization and purification of dodecanoic acid modified peptide}

The crude synthesized lipopeptides were purified by using RP-HPLC $(\mathrm{C} 18,4.6 \times 250 \mathrm{~mm})$, on the basis of $0.1 \%$ TFA/acetonitrile gradient from 0 to $80 \%$ in $48 \mathrm{~min}$. Then purified products were determined by using MALDI-TOF MS (AB, SCIEX).

\section{CD spectroscopy}

The secondary structure of peptides was confirmed in accordance with the protocol previously in our group ${ }^{1,2}$. CD spectra was recorded between $180 \mathrm{~nm}$ and $280 \mathrm{~nm}$ on a Jasco J-815 CD spectrometer. The measurement temperature was $25^{\circ} \mathrm{C}$ and peptides concentrations were diluted to $100 \mu \mathrm{M}$ with phosphate buffer solution and $50 \%$ TFE, respectively.

\section{Hemolytic activity}

Red blood cells were centrifuged with PBS buffer at $5000 \mathrm{rpm}$ for 5 minutes and totally washed three times. Cells were re-suspended in PBS to a final concentration of $1 \%$. The RBC suspension $(50 \mu \mathrm{L})$ was then mixed with another $50 \mu \mathrm{L}$ PBS solution containing $1 \%$ Triton-X 100 and different concentration of lipopeptides, PBS and 1\% Triton-X 100 are a negative control and positive control, respectively. After incubated for $1 \mathrm{~h}$ at $37^{\circ} \mathrm{C}$, the mixture was centrifuged for 5 $\min$ at $12,000 \mathrm{rpm}$. The supernatant was added to 96 -well plates to measure the absorbance at 450 $\mathrm{nm}$ by using a microplate reader. 
Figure S1. Analytical RP-HPLC and mass spectra of L- $\mathrm{C}_{12}, \mathrm{~L}-\mathrm{C}_{12}-1, \mathrm{~L}-\mathrm{C}_{12}-2, \mathrm{~L}_{-} \mathrm{C}_{12}-3, \mathrm{~L}_{-} \mathrm{C}_{12}-4$, L- $\mathrm{C}_{12}-5, \mathrm{~L}-\mathrm{C}_{12}-6$ and $\mathrm{L}-\mathrm{C}_{12}-7$,respectively. The primary purification of eight lipopeptides using RP-HPLC. The elution of the peptides was monitored at $215 \mathrm{~nm}$.

1. Analytical RP-HPLC and mass spectra of L-C $\mathrm{C}_{12}$
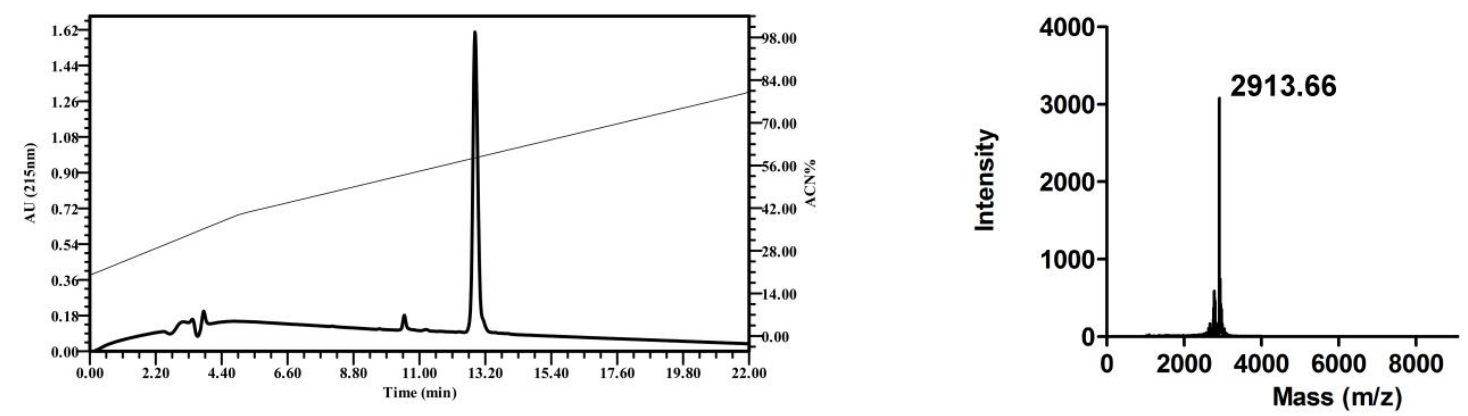

2. Analytical RP-HPLC and mass spectra of $\mathrm{L}-\mathrm{C}_{12}-1$
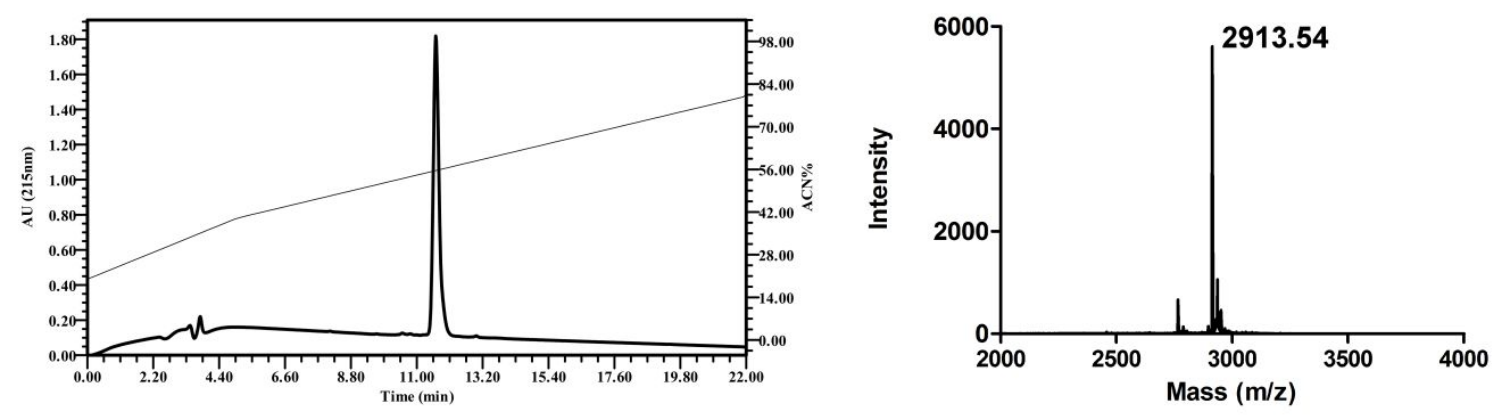

3. Analytical RP-HPLC and mass spectra of $\mathrm{L}-\mathrm{C}_{12}-2$
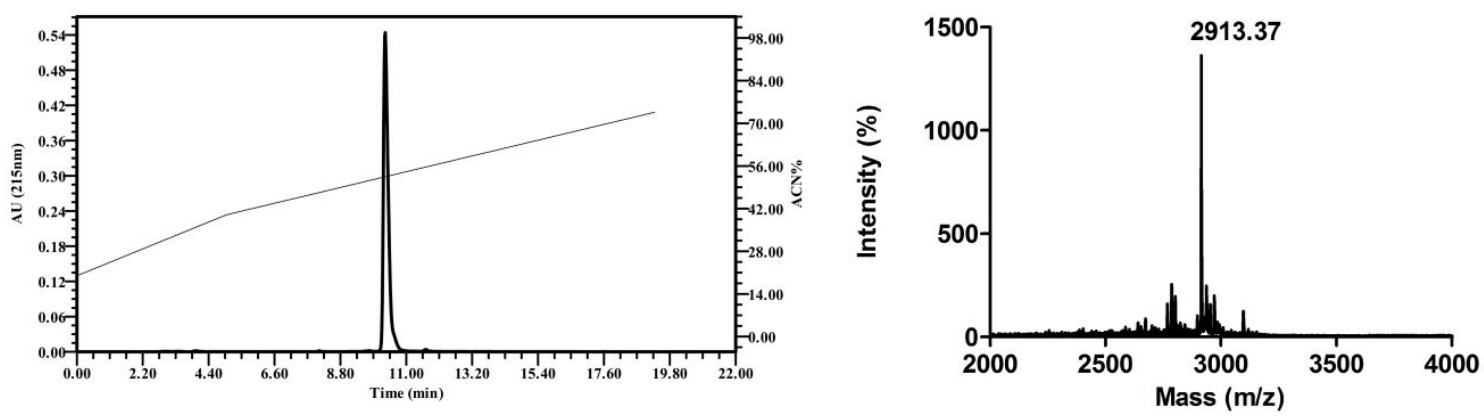

4. Analytical RP-HPLC and mass spectra of $\mathrm{L}-\mathrm{C}_{12}-3$ 

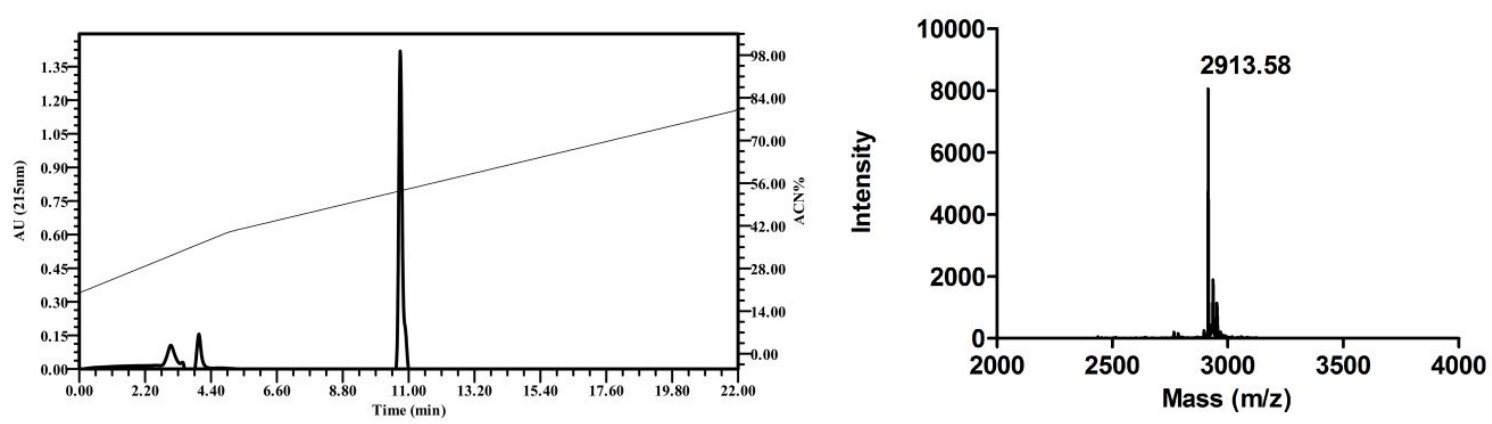

5. Analytical RP-HPLC and mass spectra of $\mathrm{L}-\mathrm{C}_{12}-4$
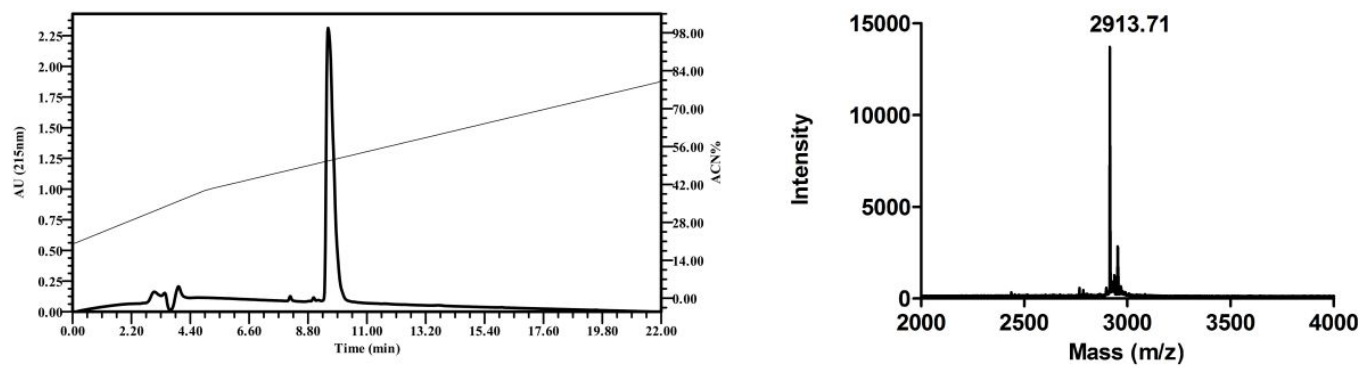

6. Analytical RP-HPLC and mass spectra of $\mathrm{L}_{-} \mathrm{C}_{12}-5$
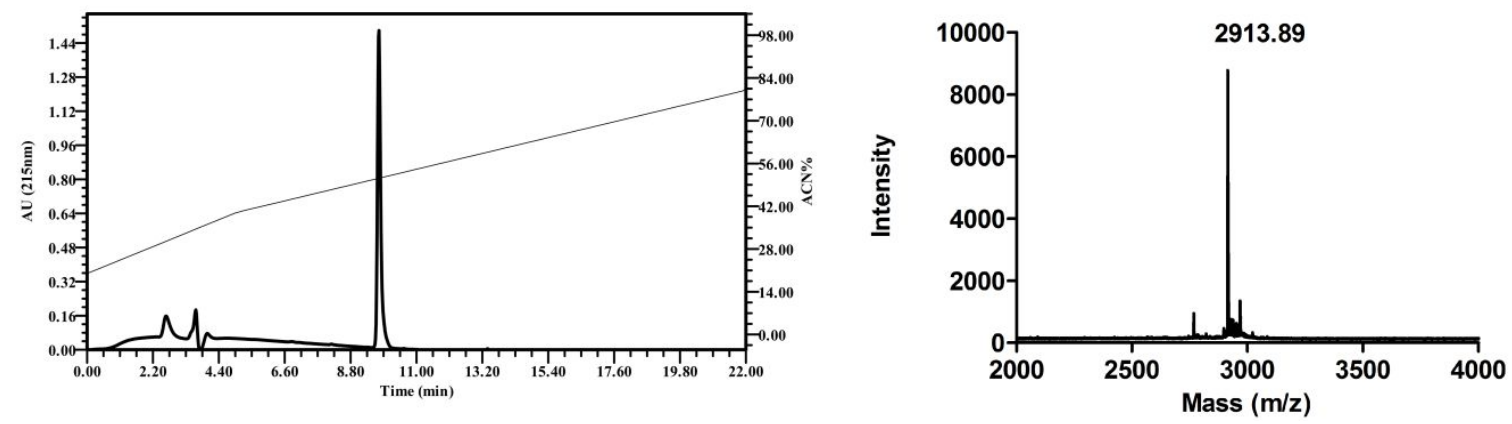

7. Analytical RP-HPLC and mass spectra of L-C $\mathrm{C}_{12}-6$
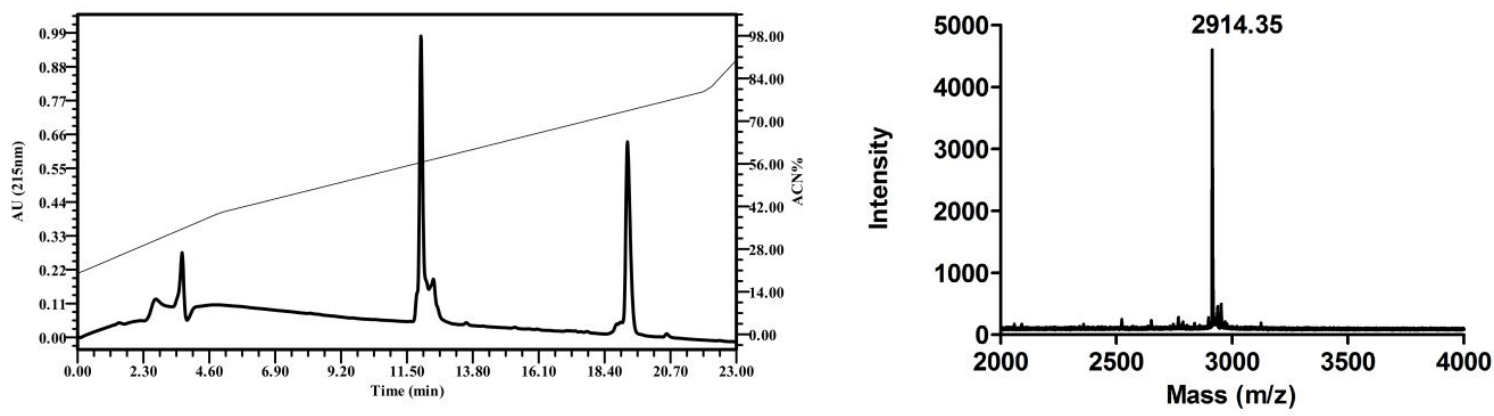

8. Analytical RP-HPLC and mass spectra of $\mathrm{L}_{-} \mathrm{C}_{12-7}-7$ 

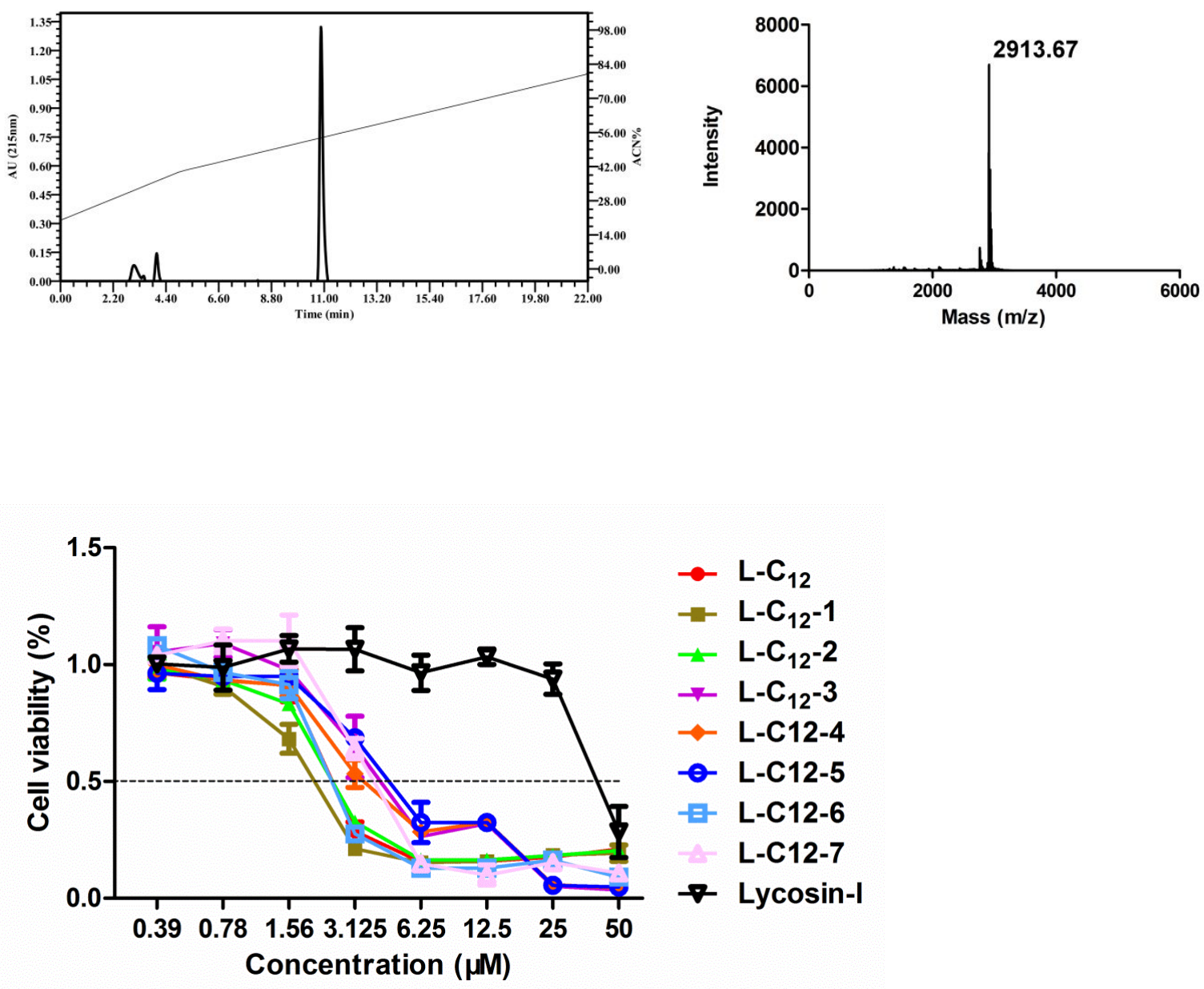

Figure S2. The cytotoxicity of Lycosin-I and lipopeptides to HEK293T cells. Cells are treated with a series concentration of peptides in serum-free medium for 24 hours.

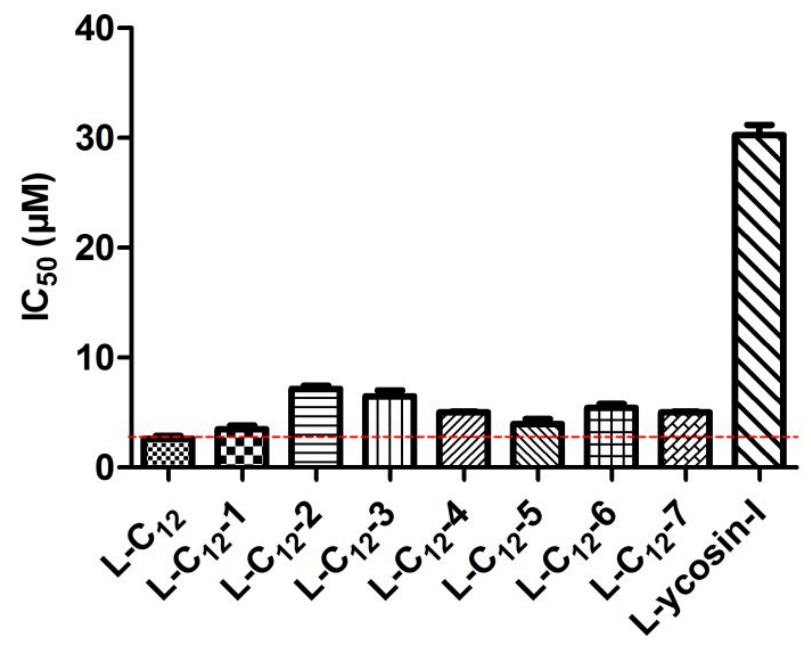

Figure S3. Live cell statistics of trypan blue staining experiments. The calculation of the number of living cells is based on the Image J pro plus software $(n=2)$. 


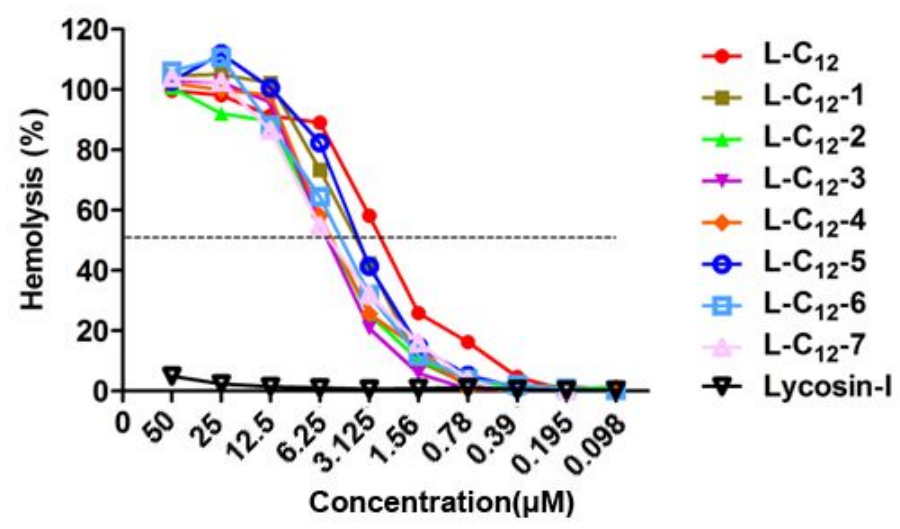

Figure S4. Hemolytic activity of Lycosin-I and lipopeptides against human erythrocytes. The absorbance of the supernatant was detected by microplate reader at $450 \mathrm{~nm}$.
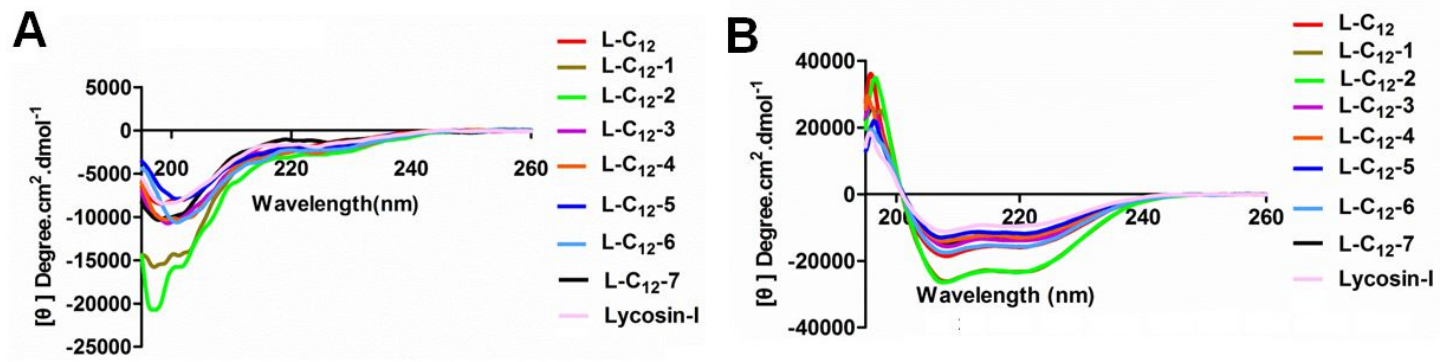

Figure S5. The secondary structure of Lycosin-I and eight lipopeptides was measured in PBS (B) and $50 \% \operatorname{TFE}(\mathrm{A})$ by circular dichroism spectrum at $25^{\circ} \mathrm{C}$ in the concentration of $100 \mu \mathrm{M}$.

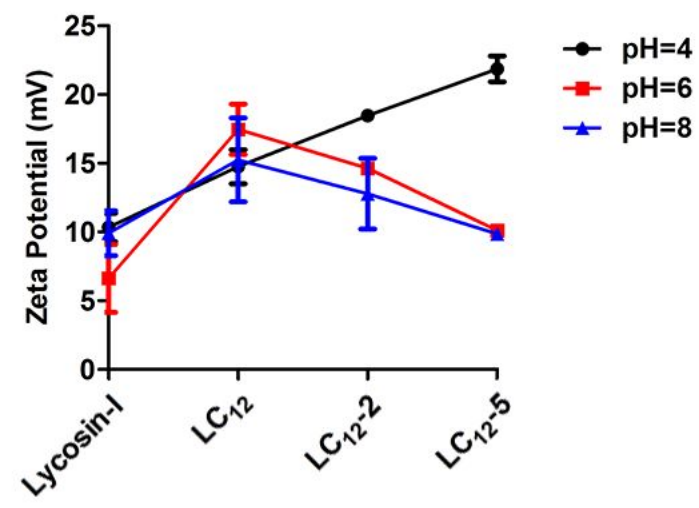

Figure S6. Zeta potential of lipopeptides at different $\mathrm{pH}$. The lipopeptides were diluted in MQ at $\mathrm{pH} 4.0,6.0$ and 8.0 to final concentration of $50 \mu \mathrm{M}$ and zeta potentials were measured. 


\section{References}

1. Jian, C.; Zhang, P.; Ma, J.; Jian, S.; Zhang, Q.; Liu, B.; Liang, S.; Liu, M.; Zeng, Y.; Liu, Z. The roles of fatty-acid modification in the activity of the anticancer peptide R-Lycosin-I. Molecular pharmaceutics 2018, 15, 4612-4620

2. Zhang, P.; Ma, J.; Zhang, Q.; Jian, S.; Sun, X.; Liu, B.; Nie, L.; Liu, M.; Liang, S.; Zeng, Y.; Liu, Z. Monosaccharide analogues of anticancer peptide R-Lycosin-I: role of monosaccharide conjugation in complexation and the potential of lung cancer targeting and therapy. Journal of medicinal chemistry 2019, 62, 7857-7873. 